\title{
ANALYSIS OF THE TRANSPORTATION LOGISTICS FOR SPENT NUCLEAR FUEL IN KOREA
}

\author{
HYO JIK LEE*, WON IL KO and KI SEOK SEO \\ Korea Atomic Energy Research Institute \\ 1045 Daedeokdaero, Yuseong, Daejeon, 305-353, Korea \\ "Corresponding author. E-mail : hyojik@kaeri.re.kr \\ Received December 18, 2009 \\ Accepted for Publication August 09, 2010
}

As a part of the back-end fuel cycle, transportation of spent nuclear fuel (SNF) from nuclear power plants (NPPs) to a fuel storage facility is very important in establishing a nuclear fuel cycle. In Korea, the accumulated amount of SNF in the NPP pools is troublesome since the temporary storage facilities at these NPP pools are expected to be full of SNF within ten years. Therefore, Korea cannot help but plan for the construction of an interim storage facility to solve this problem in the near future. Especially, a decision on several factors, such as where the interim storage facility should be located, how many casks a transport ship can carry at a time and how many casks are initially required, affect the configuration of the transportation system. In order to analyze the various possible candidate scenarios, we assumed four cases for the interim storage facility location, three cases for the load capacity that a transport ship can carry and two cases for the total amount of casks used for transportation. First, this study considered the currently accumulated amount of SNF in Korea, and the amount of SNF generated from NPPs until all NPPs are shut down. Then, how much SNF per year must be transported from the NPPs to an interim storage facility was calculated during an assumed transportation period. Second, 24 candidate transportation scenarios were constructed by a combination of the decision factors. To construct viable yearly transportation schedules for the selected 24 scenarios, we created a spreadsheet program named TranScenario, which was developed by using MS EXCEL. TranScenario can help schedulers input shipping routes and allocate transportation casks. Also, TranScenario provides information on the cask distribution in the NPPs and in the interim storage facility automatically, by displaying it in real time according to the shipping routes, cask types and cask numbers that the user generates. Once a yearly transportation schedule is established, TranScenario provides some statistical information, such as the voyage time, the availability of the interim storage facility, the number of transported casks sent from the NPPs, and the number of transported casks received at the interim storage facility. By using this information, users can verify and validate a yearly transportation schedule. In this way, the 24 candidate scenarios could be constructed easily. Finally, these 24 scenarios were compared in terms of their operation cost.

KEYWORDS : Transportation, Logistics, Scenario, EXCEL

\section{INTRODUCTION}

Korea has four reactor sites at Kori, Wolsong, Ulchin and Younggwang, all located along the coast of the Korean peninsula. A total of 20 reactors are currently being operated. Spent nuclear fuel (SNF) generated from each site are being stored inside reactor fuel buildings pending the construction of a fuel storage facility, due to be completed by the end of 2016. The accumulated amount of SNF generated from NPPs is $4,328 \mathrm{tU}$ for the sixteen pressurized water reactors (PWRs) and 5,102 tU for the four CANDU reactors, as of the end of 2007. The current storage capacity at reactors is expected to be full of SNF in 2016, even if transshipments of SNF between neighboring reactors in the same site boundary are carried out to supplement the shortage of storage capacity at the older units. According to the spent fuel management plan announced by the Korea Atomic Energy Commission (KAEC) in September 1998, a centralized interim storage facility will be completed by 2016 [1]. The storage system, dry or wet, will be determined by considering the circumstances of the facility site and the research and development progress at that time. Also, according to the spent fuel management plan announced by KAEC in December 2004, an interim storage facility plan, including its construction, will be pursued by taking into account the direction of national policy in accordance with public acceptance. Therefore, provided that the national policy confirms the building of a centralized interim storage 
facility, a great amount of transportation is forecasted.

SNF transportation is important in carrying out an SNF management plan for the back-end fuel cycle. Considering the interim storage facility and the time spent establishing the foundation of the transportation system, a study analyzing the transportation plan must be started right now. As a part of this analysis of the transportation plan, a logistics analysis was carried out by KAERI [2]. The study focuses on the estimation of the capacity of storage facilities according to generated SNF and transportation rate. However, a detailed strategy for logistics planning is not shown in that paper. In order to configure an appropriate system for SNF transportation, fleet sizing, routing and operation scheduling need to be considered. Beaujon and Turnquist [3] made a model and provided useful decision support for fleet sizing and vehicle allocation. List et al. [4] addressed the fleet sizing problem by using an optimization model that focuses on equipment investment decisions. Chang et al. [5] developed an effective method for routing problems in which the routing attributes are uncertain, with application to the routing of hazardous material shipments. In the above studies, most emphasis is placed on developing optimization algorithms for multi-objective problems, so the studies are rather difficult to use in practice.

In a narrow sense, in the field of SNF transportation, logistics is the management of the flow of SNF between the NPPs and a centralized interim storage facility in order to meet the requirements of the government or stakeholders. Thus, this paper focuses on the planning or scheduling of transportation flow for SNF such as ship routes and cask allocations. However, route scheduling and cask allocations under constraints, such as a shipping and unshipping time during a long period, are obviously tedious and error-prone tasks. To reduce errors while carrying out transportation planning or scheduling while taking constraints into account, an EXCEL based scheduling program named TranScenario was developed [6]. TranScenario speeds up route scheduling and cask allocation and also summarizes voyage time, the number of casks transported from reactor sites and the number of casks received at a centralized interim storage facility, operation time and utilization in the interim storage facility. It provides a transportation planner with many useful insights about how to operate a transportation system in terms of system operation cost.

\section{BASIC ASSUMPTIONS}

\subsection{SNF Generation and Storage}

Table 1 shows the status of SNF generation and storage in Korea [7]. Status of SNF generation is released every quarter of a year on the website of the Korea Radioactive Waste Management Corporation (KRMC) [8].

Basic SNF generation and storage data for future analysis of transportation logistics is produced with reference to an operational schedule of NPPs according to the country's third national electric power development plan, which announced that eight more nuclear units, including the six nuclear units currently being constructed, are to be constructed by 2016. Conversion of the SNF measurement unit from tU to an assembly (for PWR) or a bundle (for CANDU) is performed because SNF transportation is carried out on an assembly or bundle basis. In Table 1, site conversion factors were simply obtained from the amount of generated SNF in units of $\mathrm{tU}$ divided by the amount of generated SNF in units of assembly or bundle at each site as of the end of 2007. These conversion factors can be used when there is a need to predict the amount of generated SNF in the future in units of assembly or bundle. The amount of SNF generated from nuclear reactors depends on the number of nuclear reactors and their life times. This study only considers 28 nuclear units based on the country's third national electric power development plan. It is assumed that Shin-Kori \#3 and \#4 and Shin-Unchin \#1 and \#2 units will be operated for 60 years and the other 24 units will be operated for 40 years. The 28 nuclear units will have generated a total of 26,000 $\mathrm{tU}$ from PWRs and 15,600 $\mathrm{tU}$ from CANDUs by the time all the units are shut down [7].

Table 1. Status of SNF Generation and Storage as of the End of 2007

\begin{tabular}{c|c|c|c|c|c|c|c}
\hline \multirow{2}{*}{ Reactors } & \multicolumn{2}{|c|}{ Amount of generated SNF } & \multicolumn{2}{c|}{ Amount of stored SNF } & \multicolumn{2}{c}{ Capacity } & Conversion factor \\
\cline { 2 - 8 } & (assembly) & $(\mathrm{tU})$ & (assembly) & $(\mathrm{tU})$ & (assembly) & $(\mathrm{tU})$ & $(\mathrm{tU} / \mathrm{ass}$ 'y) \\
\hline Kori\#1 \#4 & 4,034 & 1,626 & 4,027 & 1,623 & 5,448 & 2,253 & 0.403 \\
\hline Yonggwang \#1 \#6 & 3,568 & 1,491 & 3,568 & 1,491 & 6,396 & 2,686 & 0.418 \\
\hline Ulchin \#1 \#6 & 2,864 & 1,214 & 2,864 & 1,214 & 3,910 & 1,642 & 0.424 \\
\hline \multirow{2}{*}{ Wolsong \#1 \#4 } & 269,064 & \multirow{2}{*}{5,092} & 141,084 & 2,676 & 154,512 & 2,919 & \multirow{2}{*}{0.0189} \\
\cline { 4 - 7 } & & & $127,980^{*}$ & $2,426^{*}$ & $162,000^{*}$ & $3,061^{*}$ & \\
\hline
\end{tabular}

${ }^{*}$ Quantity stored at dry storage. 


\subsection{Annual Transportation Quantity}

This study assumes that a centralized interim storage facility will be constructed by 2016 and that the transportation of SNF will start from 2017. Transportation rate is assumed for simplicity to be constant throughout the transportation period. Thus, the annual transportation quantity, which is classified by site, is defined as the total generated SNF divided by the entire transportation period, which ranges from 2017 to seven years after shut-down. Here, seven years after shut-down was determined by the condition of a seven year cooling of SNF. First, the annual transportation quantity is calculated on an assembly basis and then converted on a cask basis. This is because SNF can only be transported not on an assembly basis but on a cask basis. This study considers a cask that can contain 24 assemblies for PWR fuel and 540 bundles for CANDU fuel as one of the most appropriate cask types. Under the above assumptions, the annual transportation quantity is calculated as shown in Table 2. Since the annual transportation quantity must be an integer and not a decimal fraction, the final transportation quantity is obtained by rounding-up. Thus, the actual transportation can be done earlier than seven years after shut-down. In this case, the annual transportation quantity might be changed at around the end of transportation. However, this study only deals with one representative annual transportation quantity obtained in this way.

\subsection{Candidate Locations of Interim Storage Facility}

Regarding the location of a centralized interim storage, four candidates are investigated along the coast of the Korean peninsula. Except one candidate, the other three candidates are close to the current NPP sites (Kori, Ulchin and Yonggwang), shown in Fig. 1.

One candidate is anywhere to the north of Yonggwang. Since Wolsong already has a low intermediate level waste (LILW) disposal repository, it is excluded from the candidate locations for the centralized interim storage facility according to the national policy. In the cases of locations close to the NPP sites, transportation between the centralized interim storage facility and its closest NPP site will be done by land and other transportation between the centralized interim storage facility and distant NPP sites will be done by sea. In the case in which the centralized interim storage facility is anywhere to the north of Yonggwang, all the transportation will be done by sea.

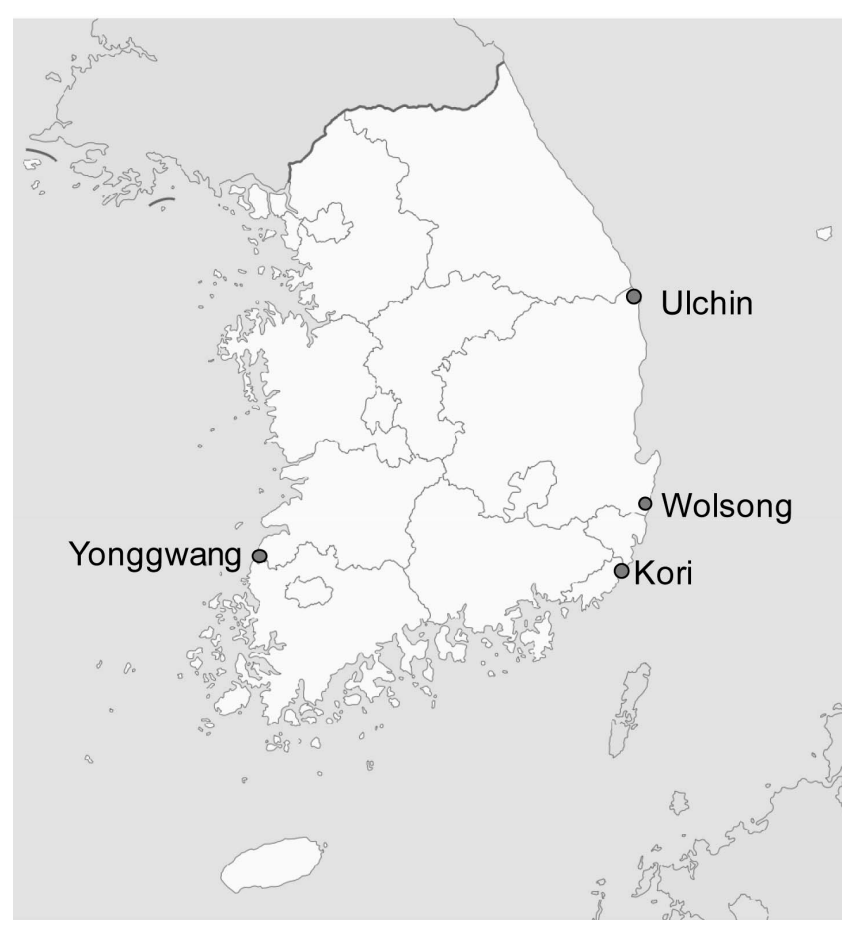

Fig. 1. Korea NPP Site Map

Table 2. Annual Transportation Quantity

\begin{tabular}{|c|c|c|c|c|c|c|c|}
\hline & & \multirow{2}{*}{$\begin{array}{l}\text { Generated quantity } \\
\text { until shut-down (tU) }\end{array}$} & \multicolumn{3}{|c|}{ Annual transportation quantity } & \multirow{2}{*}{$\begin{array}{l}\text { Entire transport } \\
\text { period (year) }\end{array}$} & \multirow{2}{*}{ Note } \\
\hline & & & $\mathrm{tU}$ & assembly & cask $^{*}$ & & \\
\hline \multirow{5}{*}{ PWR } & Kori & 9,500 & 150 & 384 & 16 & 64 & Incl. Shin-Kori \\
\hline & Yonggwang & 4,900 & 150 & 360 & 15 & 33 & \\
\hline & Ulchin & 9,400 & 145 & 360 & 15 & 66 & Incl. Shin-Ulchin \\
\hline & Shin-Wolsong & 2,200 & 55 & 144 & 6 & 41 & \\
\hline & Sub-total & 26,000 & 500 & 1,248 & 52 & & \\
\hline CANDU & Wolsong & 15,600 & 520 & 27,540 & 51 & 30 & \\
\hline \multicolumn{2}{|c|}{ Total Sum } & 41,600 & 1,020 & & 103 & & \\
\hline
\end{tabular}

${ }^{*}$ It is assumed that cask can accommodate 24 PWR assemblies or 540 CANDU bundles. 


\subsection{Voyage Time by Sea}

Voyage time is estimated by taking possible sea routes between two points into account with day units, as shown in Table 3. Sea route distance is estimated by assuming the transport ship passes the south sea of Jeju Island. Time for voyages is calculated with an average speed of $12 \mathrm{knot} / \mathrm{h}$ $(22.2 \mathrm{~km} / \mathrm{h})$ with rounding up to the day unit.

\section{TRANSPORTATION SCENARIOS}

\subsection{Screening Scenarios}

In order to make reasonable scenarios, there are important factors to be decided. Besides the location of the centralized interim storage facility, there are two more important factors. One is the load capacity that a transport ship carries at a time and the other is the total number of casks to be used for transportation. This paper considers a transport ship that can carry four types of casks such as empty PWR casks, loaded PWR casks, empty CANDU casks and loaded CANDU casks with a maximum of 8, 10 and 12 casks and the total number of casks that is one times and two times as many as a ship's capacity. Thus, possible scenarios are a total of $24(=4 \times 3 \times 2)$ cases. These three factors also affect the configuration of the transportation system as well as the scenario generation.

\subsection{Scenario Generation Using TranScenario}

To generate 24 scenarios to satisfy the annual transportation quantity, an EXCEL based scenario generation program named TranScenario was developed. This program can rapidly establish up to a year's scheduling and planning for SNF transportation, such as route generation and cask allocations. Users such as schedulers or planners must input decision variables, which are where a transport ship is heading and coming from, the cask type and the cask quantity that a ship is carrying at that moment. Cask type is classified into four categories; empty PWR cask, loaded PWR cask, empty CANDU cask and loaded CANDU cask. Figure 2 shows a screen shot of the TranScenario. For a yearly transportation schedule, a total of 365 (days) multiplied by 6 (decision variables) must be defined by users.

Two decision variables related to ship routes (where a transport ship is heading and coming from) and four decision variables related to cask allocations (cask quantity by type) are required as input variables every day. Figure 2 shows a yearly schedule in the case in which the centralized interim storage is located near the Kori site, the load capacity of a ship is 12 casks, and the total number of casks to be used is 24 casks for the PWR SNF and 24 casks for CANDU SNF. We also assumed that the working times to load and receive/store SNF assemblies or bundles, to and from a cask, respectively, are defined as shown in the top right table in Fig. 2. It is assumed that loading the SNF assemblies or bundles into a cask at NPP sites is done simultaneously in two reactors and that the centralized interim storage has PWR and CANDU lines, independently. Cells consisting of rows from 41 to 405 and columns from $\mathrm{K}$ to $\mathrm{X}$ are automatically calculated every time the decision variables consisting of rows from 41 to 405 and columns from $\mathrm{E}$ to $\mathrm{J}$ are inserted as new values. The cells from rows 41 to 405 and from column $\mathrm{K}$ to $\mathrm{X}$ provide useful information about cask allocations at NPP sites and the interim storage facility to help users input the next decision variables.

Each column of the worksheet table in Fig. 2 has the following meanings:

- Column A, t(day) : time on a daily basis.

- Column E, R_s(t) : departure site of transport ship at time t.

- Column F, R_e(t) : destination site of transport ship at time $\mathrm{t}$.

- Column G, C_load(t,1) : the number of loaded PWRcasks being transported by transport ship at time $t$.

- Column H, C_load(t,2) : the number of loaded CANDUcasks being transported by transport ship at time $\mathrm{t}$.

Table 3. Voyage Time (Days)

\begin{tabular}{c|c|c|c|c|c}
\hline Route & $\begin{array}{c}\text { Voyage distance } \\
\text { (estimated time) }\end{array}$ & Assumed voyage time & Route & $\begin{array}{c}\text { Voyage distance } \\
\text { (estimated time) }\end{array}$ & Assumed voyage time* \\
\hline $\mathrm{KR} \leftrightarrow \mathrm{WS}$ & $75 \mathrm{~km}$ (4 hours) & 1 day & $\mathrm{YG} \leftrightarrow \mathrm{WS}$ & $900 \mathrm{~km}$ (41 hours) & 2 days \\
\hline $\mathrm{KR} \leftrightarrow \mathrm{UC}$ & $265 \mathrm{~km}$ (12 hours) & 1 day & $\mathrm{NYG} \leftrightarrow \mathrm{KR}$ & $905 \mathrm{~km}$ (41 hours) & 2 days \\
\hline $\mathrm{KR} \leftrightarrow \mathrm{YG}$ & $825 \mathrm{~km}(38$ hours) & 2 days & $\mathrm{NYG} \leftrightarrow \mathrm{WS}$ & $980 \mathrm{~km}$ (44 hours) & 2 days \\
\hline $\mathrm{UC} \leftrightarrow \mathrm{WS}$ & $190 \mathrm{~km}(9$ hours) & 1 day & $\mathrm{NYG} \leftrightarrow \mathrm{UC}$ & $1,220 \mathrm{~km}$ (55 hours) & 3 days \\
\hline $\mathrm{UC} \leftrightarrow \mathrm{YG}$ & $1,140 \mathrm{~km}(52$ hours) & 3 days & $\mathrm{NYG} \leftrightarrow \mathrm{YG}$ & $80 \mathrm{~km}$ (4 hours) & 1 day \\
\hline
\end{tabular}

KR: Kori, WS: Wolsong, UC: Ulchin, YG: Yonggwang, NYG: North of Yonggwang

${ }^{*}$ It is understood that assumed voyage time is calculated by simply rounding up estimated voyage time. 
- Column I, C_unl(t,1) : the number of empty PWRcasks being transported by transport ship at time $\mathrm{t}$.

- Column J, C_unl( $(t, 2)$ : the number of empty CANDUcasks being transported by transport ship at time $t$.

- Column K, I_load(t,1) : the number of loaded PWRcasks allocated at interim storage at time $t$.

- Column L, I_load(t,2) : the number of loaded CANDUcasks allocated at interim storage at time $\mathrm{t}$.

- Column M, I_unl(t,1) : the number of empty PWRcasks allocated at interim storage at time $t$.

- Column N, I_unl(t,2) : the number of empty CANDUcasks allocated at interim storage at time $\mathrm{t}$.

- Column O, K_load(t,1) : the number of loaded PWRcasks allocated at Kori at time $t$.

- Column P, K_unl $(t, 1)$ : the number of empty PWRcasks allocated at Kori at time $\mathrm{t}$.

- Column Q, Y_load(t,1) : the number of loaded PWRcasks allocated at Yonggwang at time t.

- Column R, Y_unl(t,1) : the number of empty PWRcasks allocated at Yonggwang at time t.

- Column S, U_load(t,1) : the number of loaded PWRcasks allocated at Ulchin at time t.

- Column T, U_unl $(t, 1)$ : the number of empty PWRcasks allocated at Ulchin at time t.

- Column U, W_load(t,1) : the number of loaded PWRcasks allocated at Shin-Wolsong at time t.

- Column V, W_load(t,2) : the number of loaded CANDU-casks allocated at Wolsong at time t.

- Column W, W_unl $(t, 1)$ : the number of empty PWRcasks allocated at Shin-Wolsong at time t.
- Column X, W_unl $(\mathrm{t}, 2)$ : the number of empty CANDUcasks allocated at Wolsong at time $t$.

If users complete inputting $2190(=365 \times 6)$ decision variables, the three tables shown in the bottom of Fig. 2 verify whether the input data is faultless. The first table shows how many casks are sent from NPP sites and how many casks are received at the interim storage facility. The second table shows the voyage time according to the two definitions, which will be explained in 3.4. The third table shows the operation time and the utilization of the centralized interim storage facility.

\subsection{Scenario Generation Rules}

Consistent scenario generation is important because a user's preference should be rejected as much as possible while making an annual schedule. If 24 scenarios are generated without consistent rules, the comparison among the 24 scenarios will be meaningless. Therefore, minimum rules are needed to make annual schedules suited for fair and objective comparison between the 24 scenarios. In order to consistently make the 24 scenarios, some basic rules are taken into account, as follows:

- Basic route between the centralized interim storage facility and an NPP site is a round-trip.

- Shipping starts once a loading finishes if a transport ship is waiting at that time.

- Once a shipping is completed, transport ship departs.

- After a partial shipping of the loaded casks at an NPP site, the transport ship is not allowed to stop at other NPP sites for a shipping of the rest.

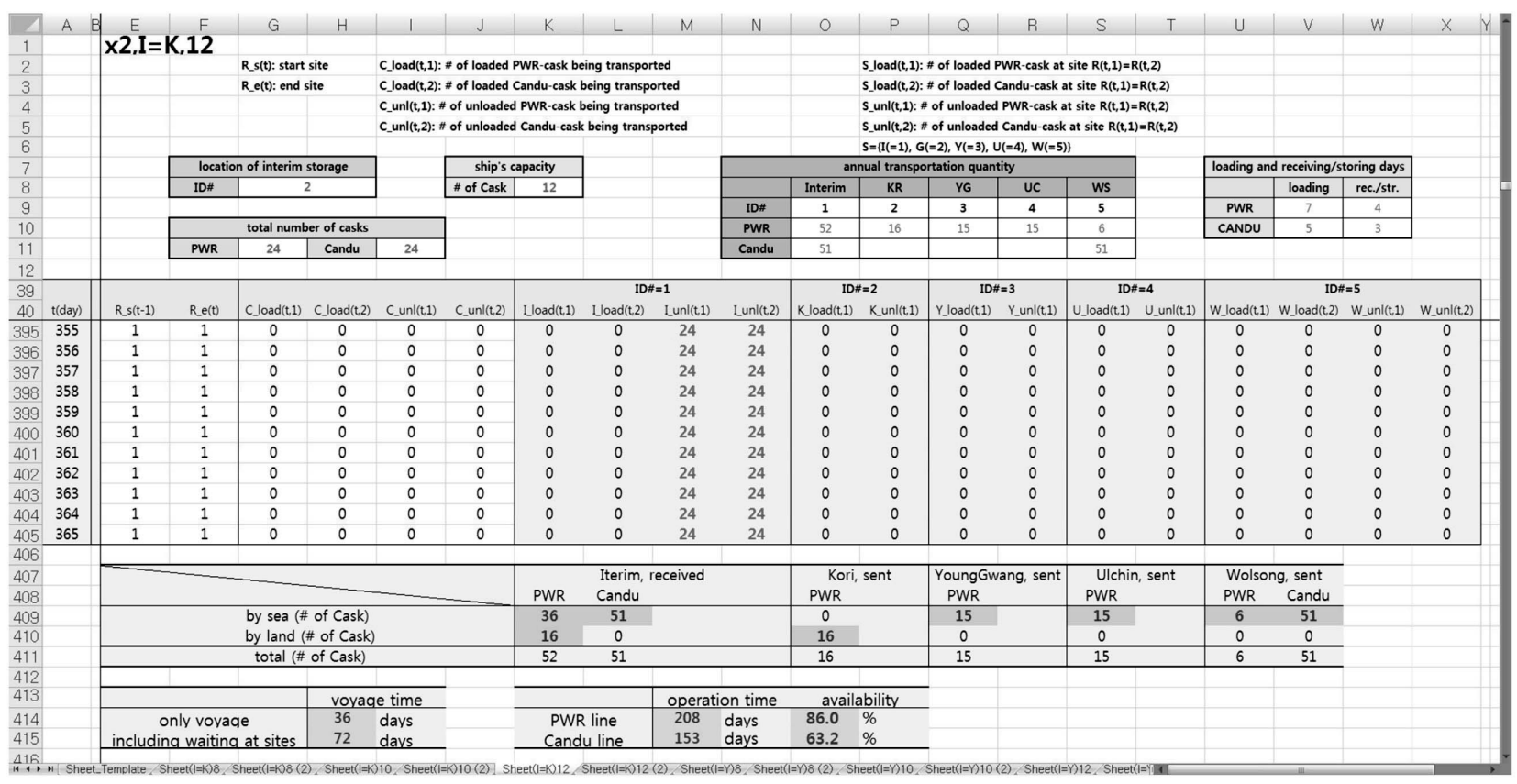

Fig. 2. TranScenario 
- After a partial unshipping of the empty casks at an NPP site, the transport ship is allowed to stop at other NPP sites for an unshipping of the rest.

- After a full unshipping of the empty casks at an NPP site, the transport ship is allowed to stop at other NPP sites for a shipping of some loaded casks.

Even if the above basic rules are applied, there may be many alternatives to the scenarios. However, generated under the above rules, the scenarios do not deviate much in terms of comparison criteria such as voyage time, availability and total operation time. The basic rules play a role in narrowing the deviation of the comparison criteria.

\subsection{Definitions of Terms}

For a scenario comparison, frequently used terms are defined as follows:

- Voyage time: Voyage time means only the time for a transport ship to undertake voyage. The other definition of the voyage time includes the anchorage time at NPP sites.

- Total operation time: Total time for voyage, shipping and unshipping, loading and receiving/storing, i.e. a period during which a yearly transportation schedule is implemented.

Table 4. Comparison of 24 Scenarios

\begin{tabular}{|c|c|c|c|c|c|c|c|}
\hline \multirow{2}{*}{\multicolumn{2}{|c|}{ Scenarios }} & \multicolumn{2}{|c|}{ Voyage time (days) } & \multicolumn{2}{|c|}{ Availability (\%) } & \multirow{3}{*}{$\begin{array}{c}\begin{array}{c}\text { Total operation } \\
\text { time }\end{array} \\
273\end{array}$} & \multirow{3}{*}{$\begin{array}{c}\text { Remark } \\
\text { SUCCESS }\end{array}$} \\
\hline & & \multirow{2}{*}{$\begin{array}{c}\begin{array}{c}\text { Only } \\
\text { voyage }\end{array} \\
42\end{array}$} & \multirow{2}{*}{$\begin{array}{c}\begin{array}{c}\text { Including } \\
\text { anchorage }\end{array} \\
90\end{array}$} & \multirow{2}{*}{$\begin{array}{c}\text { PWR line } \\
76.2\end{array}$} & \multirow{2}{*}{$\begin{array}{c}\text { CANDU } \\
\text { line }\end{array}$} & & \\
\hline \multirow{12}{*}{$\begin{array}{l}\text { Total number of } \\
\text { casks: } \\
\text { Ship capacity } \times 2\end{array}$} & $\mathrm{I}=\mathrm{K}, 8$ & & & & & & \\
\hline & $\mathrm{I}=\mathrm{K}, 10$ & 38 & 78 & 82.9 & 61.0 & 251 & SUCCESS \\
\hline & $\mathrm{I}=\mathrm{K}, 12$ & 36 & 72 & 86.0 & 63.2 & 242 & SUCCESS \\
\hline & $\mathrm{I}=\mathrm{Y}, 8$ & 68 & 117 & 84.2 & 61.9 & 247 & SUCCESS \\
\hline & $\mathrm{I}=\mathrm{Y}, 10$ & 60 & 101 & 79.7 & 58.6 & 261 & SUCCESS \\
\hline & $\mathrm{I}=\mathrm{Y}, 12$ & 56 & 93 & 83.2 & 61.2 & 250 & SUCCESS \\
\hline & $\mathrm{I}=\mathrm{U}, 8$ & 48 & 96 & 86.3 & 63.5 & 241 & SUCCESS \\
\hline & $\mathrm{I}=\mathrm{U}, 10$ & 45 & 85 & 81.6 & 60.0 & 255 & SUCCESS \\
\hline & $\mathrm{I}=\mathrm{U}, 12$ & 42 & 78 & 85.2 & 62.7 & 244 & SUCCESS \\
\hline & $\mathrm{I}=\mathrm{NY}, 8$ & 73 & 130 & 64.4 & 47.4 & 323 & SUCCESS \\
\hline & $\mathrm{I}=\mathrm{NY}, 10$ & 66 & 115 & 62.7 & 46.1 & 332 & SUCCESS \\
\hline & $\mathrm{I}=\mathrm{NY}, 12$ & 61 & 106 & 66.5 & 48.9 & 313 & SUCCESS \\
\hline \multirow{12}{*}{$\begin{array}{l}\text { Total number of } \\
\text { casks: } \\
\text { Ship capacity } \times 1\end{array}$} & $\mathrm{I}=\mathrm{K}, 8$ & 55 & 103 & 57.6 & 42.4 & 364 & SUCCESS \\
\hline & $\mathrm{I}=\mathrm{K}, 10$ & 46 & 86 & 59.8 & 44.0 & 355 & SUCCESS \\
\hline & $\mathrm{I}=\mathrm{K}, 12$ & 43 & 83 & 62.3 & 45.8 & 339 & SUCCESS \\
\hline & $\mathrm{I}=\mathrm{Y}, 8$ & $\mathrm{n} / \mathrm{a}$ & $\mathrm{n} / \mathrm{a}$ & 51.8 & 39.5 & $\mathrm{n} / \mathrm{a}$ & FAIL \\
\hline & $\mathrm{I}=\mathrm{Y}, 10$ & $\mathrm{n} / \mathrm{a}$ & $\mathrm{n} / \mathrm{a}$ & 57.0 & 41.1 & $\mathrm{n} / \mathrm{a}$ & FAIL \\
\hline & $\mathrm{I}=\mathrm{Y}, 12$ & 74 & 118 & 59.9 & 44.1 & 350 & SUCCESS \\
\hline & $\mathrm{I}=\mathrm{U}, 8$ & $\mathrm{n} / \mathrm{a}$ & $\mathrm{n} / \mathrm{a}$ & 55.1 & 41.4 & $\mathrm{n} / \mathrm{a}$ & FAIL \\
\hline & $\mathrm{I}=\mathrm{U}, 10$ & 56 & 104 & 59.1 & 43.5 & 356 & SUCCESS \\
\hline & $\mathrm{I}=\mathrm{U}, 12$ & 51 & 95 & 61.5 & 45.3 & 341 & SUCCESS \\
\hline & $\mathrm{I}=\mathrm{NY}, 8$ & $\mathrm{n} / \mathrm{a}$ & $\mathrm{n} / \mathrm{a}$ & 41.4 & 39.5 & $\mathrm{n} / \mathrm{a}$ & FAIL \\
\hline & $\mathrm{I}=\mathrm{NY}, 10$ & $\mathrm{n} / \mathrm{a}$ & $\mathrm{n} / \mathrm{a}$ & 43.8 & 41.1 & $\mathrm{n} / \mathrm{a}$ & FAIL \\
\hline & $\mathrm{I}=\mathrm{NY}, 12$ & $\mathrm{n} / \mathrm{a}$ & $\mathrm{n} / \mathrm{a}$ & 43.8 & 41.9 & $\mathrm{n} / \mathrm{a}$ & FAIL \\
\hline
\end{tabular}

$\mathrm{I}=\mathrm{K}, 8$ means that the interim storage facility is located near the Kori site and ship capacity is 8 casks. 
- Operation time: Time for receiving/storing at the centralized interim storage facility.

- Availability: Operation time divided by the total operation time.

\section{COMPARISON OF SCENARIOS}

\subsection{Overall Comparison}

The 24 generated scenarios are compared in Table 4 in terms of their voyage time, availability, total operation time and whether the annual transportation quantity can be transported within 365 days.

If a yearly transportation schedule cannot be generated, it means that the total operation time exceeds 365 days and the case is marked as FAIL in the remark column. Six scenarios out of the 24 scenarios could not be generated within a year. All of them come from the cases in which the total number of casks is one times as many as a ship's capacity, since it takes time to obtain available casks for the next transportation. If a ship's capacity increases, the

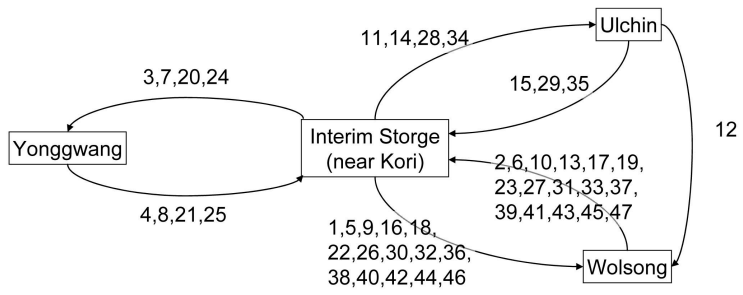

Fig. 3. A Diagram of Transport Ship's Routes for the Case in Which the Centralized Interim Storage is at Kori, a Ship's Capacity is 12 Casks and the Total Number of Casks is Two Times as Many as a Ship's Capacity

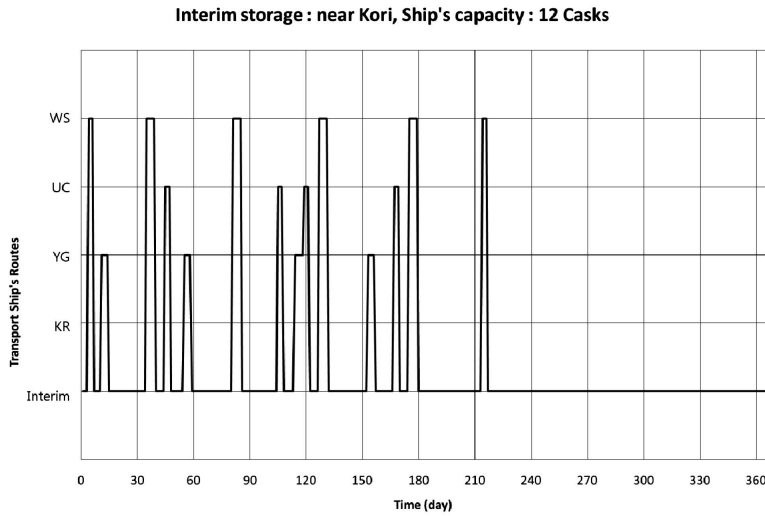

Fig. 4. Transport Ship's Routes According to Time for the Case in Which the Centralized Interim Storage is at Kori, a Ship's Capacity is 12 Casks and the Total Number of Casks is Two Times as Many as a Ship's Capacity voyage time decreases. The case in which the total number of casks is two times as many as a ship's capacity decreases the voyage time when compared to the case in which the total number of casks is one times as many as a ship's capacity. Regarding the location of the centralized interim storage facility, the Kori site is the most advantageous; on the other hand, north of Yonggwang is the most disadvantageous in terms of the voyage time.

For example, in the case in which the centralized interim storage is at Kori, a ship's capacity is 12 casks and the total number of casks is two times as many as a ship's capacity, transport ship routes are displayed in Fig. 3 and 4. An annual schedule is generated according to the basic scenario generation rules given in 3.3. In Fig. 3, the transport ship routes are displayed with arrows with the sequential numbers representing order. As a result, the total number of routes is 27 and the voyage time, including waiting time at site, is 72 days. This is not the only solution because an annual schedule depends on a user's preferences. There might be many alternatives to the scenario but their deviations are expected to be not that great because of the application of the basic rules of scenario generation. This situation can raise the problem of how to obtain an optimized solution to a certain scenario. However, this study does not address this problem because it is out of the current scope. It is left for further study.

\subsection{Voyage Time}

A detailed comparison of the 24 scenarios in terms of voyage time is shown in Fig. 5 using a bar graph. All of the three decision factors affect the voyage time of the transport ship. In the case in which the centralized interim storage is located near the Kori site, a ship's capacity is 12 casks, and the total number of casks is two times as many as a ship's capacity, the voyage time is the shortest. This means that this case is the most economical in terms

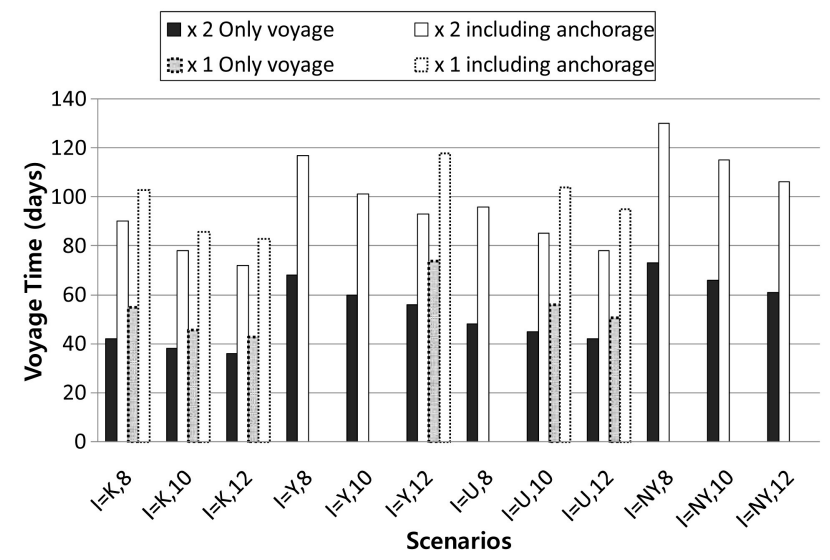

Fig. 5. Voyage Time 
of operation cost. On the other hand, the cases in which the centralized interim storage is located near the north of Yonggwang, voyage time is the longest. As the capacity of a transport ship increases, voyage time decreases. Since the total number of casks is assumed in this study to be one or two times as many as the transport ship's capacity, the increase of transport ship's capacity means the increase of initial capital cost. Therefore, the total number of casks increasing the capital cost cannot be increased without a particular plan in mind to reduce the voyage time.

\subsection{Availability}

Total operation time and availability are defined as follows: Total operation time is the time in which annual operation at centralized interim storage facility is finished; Availability is the time required to receive and store the annual transportation quantity of SNF at the centralized interim storage facility divided by the total operation time. Availability of the centralized interim storage facility is in inverse proportion to the total operation time and is automatically calculated when the annual transportation scheduling is finished in the scheduling sheet of TranScenario. If an annual transportation scheduling cannot be done within 365 days, the availability is calculated by assuming that the total operation time is 365 days. High availability means annual transportation scheduling takes a short time; on the other hand, low availability means annual transportation scheduling takes a long time. High availability can provide enough time to maintain and repair a facility, so it is advantageous over low availability. Figure 6 shows the availability comparison results for the 24 scenarios. When the total operation time exceeds 365 days, i.e., a transportation schedule cannot meet the annual transportation quantity, availability is calculated by assuming that the total operation time is 365 days. As a result, except for the cases of north Yonggwang, others have a similar availability.

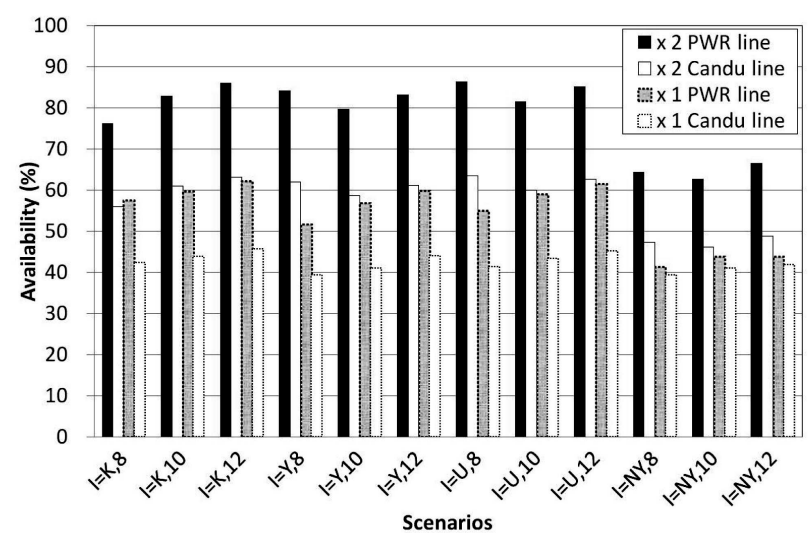

Fig. 6. Availability

\section{CONCLUSIONS}

In this study, three important decision factors to configure a transportation system were considered to generate 24 scenarios. To generate these scenarios rapidly, a program named TranScenario was developed. This program is expected to provide decision makers with a reliable, effective and rapid transportation schedule with various functions such as automatic display of statistical results and information on the cask allocations. Among the 24 generated scenarios, based on the generation rules, the case in which the centralized interim storage is located near the Kori site, a ship's capacity is 12 casks, and the total number of casks is 24 for PWR SNF and 24 for CANDU SNF, is the most economical scenario in terms of voyage time; however, annual maintenance and repair cost of casks is expected to be higher than those values for other scenarios. In this case, the initial capital cost to purchase the number of casks is the most expensive component compared to the other scenarios. More cost analysis is needed, taking into account all factors affecting the operating and capital cost. A detailed cost analysis will be considered in further studies.

\section{ACKNOWLEDGMENTS}

This work was supported by the Nuclear Research \& Development Program of the National Research Foundation of Korea (NRF) funded by the Ministry of Education, Science \& Technology (MEST).

\section{REFERENCES}

[ 1 ] H. S. Park, J. Choi, "The Current Status of Spent Nuclear Fuel in Korea," An International Spent Nuclear Fuel Storage Facility-Exploring a Russian Site as a Prototype, pp. 109117, 2005.

[2 ] H. J. Choi, J. H. Cha, J. Choi, "Development of a computer program for the analysis of logistics of PWR spent fuels," Journal of the Korean Radioactive Waste Society. 6, pp. 147-154, 2008.

[ 3 ] G. J. Beaujon and M. A. Turnquist, "A model for fleet sizing and vehicle allocation," Transport. Sci. 25, pp. 19-45. 1991.

[ 4 ] G. F. List, B. Wood, M. A. Turnquist, L. K. Nozick, D. A. Jones, C. R. Lawton, "Logistics planning under uncertainty for disposition of radioactive wastes," Comput. Oper. Res. 33, pp. 701-723, 2006.

[ 5 ] T. S. Chang, L. K. Nozick, M. A. Turnquist, "Multiobjective path finding in stochastic dynamic networks with application to routing hazardous materials shipments," Transport. Sci. 39, pp. 383-399, 2005.

[ 6 ] H. J. Lee et al., TranScenario v1.0, 2008-01-114-009594, Korean Program registration, 2008.

[ 7 ] W. I. Ko et al., Contract Report for Option Study of Spent Nuclear Fuel Transportation. KAERI/CR-320/2008, 2008.

[ 8 ] http://www.krmc.or.kr 